\title{
Description of the universal model of design system
}

\author{
Sergey Sinenko ${ }^{1 *}$, Mukhammet Fakhratov ${ }^{1}$ and Mohammad Sharif Akbari ${ }^{1}$ \\ ${ }^{1}$ Russia Moscow State University of Civil Engineering (National Research University), 129337, 26, \\ Yaroslavskoye shosse, Moscow, Russia
}

\begin{abstract}
The article proposes one way to describe the design model. Definitions of the basic concepts of design are given. The design process is considered as a certain representation of the project for the construction of an object in all conditions. Design routes, design operations algorithms, including tools for evaluating user indicators, methods for determining design resources, describe it. The description forms are well known to everyone: maps, circuits, matrix, linear and network models, etc. A model of a design system is considered. The mathematical description of design procedures allows for a deeper analysis and generalization of design analysis data. In a production design system, which is a particular type of more general organizational system, each element has a specific production role associated with a particular person's position in the production team. Thus, the elemental base of the design system is formed by subsystems, their elements, designers, and each designer carry out the conversion of resources. The model is illustrated by an example. The concepts introduced in the article and the proposed model make it possible to define organizational management as a process of redistributing the organizational system modules over technological and information modules.
\end{abstract}

\section{Introduction}

Previous studies have shown that design is usually considered as a set of operations performed by the designer when creating a project and functions in other areas. This is an informational labour process. It includes operation, reception, action (preliminary, main, verification), movement - having different characteristics (duration, labour, resources, etc.), place and implementation methods [1-9].

The purpose of this study was to show that design can be divided into parts in accordance with the nomenclature of the issued documentation (PED - Project-estimated documentation). In this case, the design refers to the development of integrated technical documentation (project) containing a feasible study, calculations, drawings, layouts, estimates, explanatory notes and other materials necessary for the construction or reconstruction of buildings and structures and their complexes [2].

\footnotetext{
* Corresponding author: sasin50@gmail.com
} 
Studying the design process shows that it has a hierarchical, iterative nature. The iterative nature is determined by the absence of an algorithm by which synthesis (PED) can be carried out immediately.

The design process is an adequate representation of the project for the construction of an object in all conditions. Design routes, design operations algorithms, including tools for evaluating custom indicators, methods for determining design resources, describe it. Forms of description are maps, circuits, matrix, linear and network models, etc. [3, 10-15].

The scientific hypothesis put forward and confirmed that the Design System is an activity in a multi-level space in which the applied tools and techniques do not function on the same plane, much less along the same line. The starting point for the formation of this spatial form is obviously arbitrary. Moreover, the designer also does not know the number and nature of individual procedures on the way from the starting point to the result. The appearance of a visual form can occur instantly, intuitively or as a result of a long search, analytically or unconsciously [3, 10-15].

\section{Methodology}

Nowadays, the development of various projects is engaged not one designer, but a group or a whole design institute.

We make assumptions and give their justification. A rigorous mathematical definition of the concept of organizational structure as the most important characteristic of a management system.

Among the many characteristics of systems, the structure occupies a special position and the mathematical description of the design procedures will make it possible to conduct a deep analysis and generalization of data. This is due to the fact that the structure is, firstly, the most general and, secondly, the most stable characteristic of the system, invariant with respect to the specific execution of its elements and changes in its state, i.e. structure reflects the most general, essential and at the same time stable properties of the system.

\section{Results}

Since the concept of "structure" is organically connected with the concepts of "system" and "system element", it is advisable to give their definition in advance.

We define the general system " $\mathrm{S}$ " as a relation defined on nonempty abstract sets $\mathrm{V}_{\mathrm{i}}(\mathrm{i} \in$ $\mathrm{Y})$ called objects of the system " $\mathrm{S}$ " [1].

$\mathrm{S} \subset \mathrm{x}\left\{\mathrm{V}_{\mathrm{i}}, \mathrm{i} € \mathrm{Y}\right\},(1.1)$, Where: $\mathrm{x}$ - a symbol of the Cartesian product;

$\mathrm{Y}$ - Many indexes of "S" system objects.

Thus, a system is defined as a certain subset of the Cartesian product of system objects.

The system objects $\mathrm{V}_{\mathrm{i}}$ consist of $\mathrm{v} \subset \mathrm{V}_{\mathrm{i}}$ elements. The set of these system objects can be divided into three pairwise disjoint subsets:

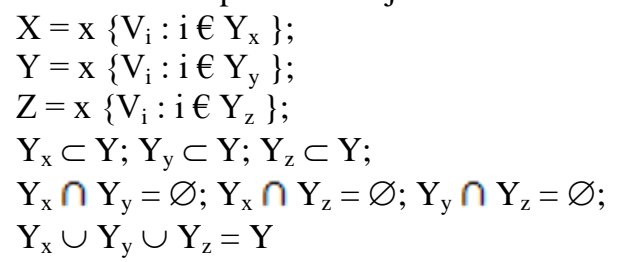

Where: $\mathrm{X}$ - many systems input (multiple inputs);

Y - A lot of output system objects (multiple exits);

$\mathrm{Z}$ - A lot of system status objects (multiple states).

The " $\mathrm{S}$ " system is made up of structural elements " $\mathrm{S}_{0}$ ". 
The structural element of the " $\mathrm{S}_{0}$ " system " $\mathrm{S}$ " is called its subsystem, the internal structure, which we do not determine and which is using from other subsystems, it is possible to form the original system $\mathrm{S}$. Thus, the structural element is so. System $\mathrm{S}$ is a private type of common system (I.I) called the "input-output" system:

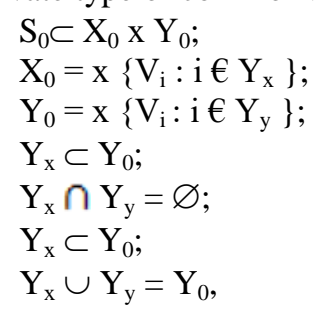

Where: $\mathrm{Y}_{0}$ - Many indices of objects of the subsystem $\mathrm{s}_{0}$;

$\mathrm{X}_{0}$ - the set of input objects of the so element or the input of this element;

$\mathrm{Y}_{0}$ - the set of output objects of the so element or the output of this element.

The set of all structural elements of the system forms its element base $\mathrm{E}_{0}$.

$\mathrm{s}_{\mathrm{o}} € \mathrm{E}_{0}$,

$\mathrm{s}_{\mathrm{o}} \subset \mathrm{S}$

Dividing many $\mathrm{E}_{0}$ with the help of the relation $\mathrm{R}_{0} \subset \mathrm{E}_{0} \times \mathrm{E}_{0}$ into pairwise disjoint subsets giving the sum of the set $\mathrm{E}_{0}$, we thus represent the set $\mathrm{E}_{0}$ as an equivalence class.

Suppose that the set E0 consists of six elements:

$\mathrm{s}_{\mathrm{o}} € \mathrm{E}_{0}(\mathrm{i}=1,6)$ 1.

$\mathrm{E} 0=\left\{\mathrm{s}_{01}, \mathrm{~s}_{02}, \mathrm{~s}_{03}, \mathrm{~s}_{04}, \mathrm{~s}_{05}, \mathrm{~s}_{06}\right\}$, and the equivalency ratio $\mathrm{R} 0 \subset \mathrm{E} 0 \mathrm{x} \mathrm{E} 0$ is given in Table

Table 1. Matrix form of representation of equivalence classes

\begin{tabular}{|c|c|c|c|c|c|c|}
\hline & $\mathrm{s}_{01}$ & $\mathrm{~s}_{02}$ & $\mathrm{~s}_{03}$ & $\mathrm{~s}_{04}$ & $\mathrm{~s}_{05}$ & $\mathrm{~s}_{06}$ \\
\hline $\mathrm{s}_{01}$ & 1 & & & & & \\
\hline $\mathrm{s}_{02}$ & & 1 & 1 & & & 1 \\
\hline $\mathrm{s}_{03}$ & & 1 & 1 & & 1 & 1 \\
\hline $\mathrm{s}_{04}$ & & & & 1 & 1 & \\
\hline $\mathrm{s}_{05}$ & & & & 1 & 1 & 1 \\
\hline $\mathrm{s}_{06}$ & & 1 & 1 & & & \\
\hline
\end{tabular}

This form is an asymmetrical matrix in which out of many pairs of elements, the pairs in which the elements that make up the pair are equivalent to each other are singled out in units. It is easy to show that the Ratio $\mathrm{R}_{0}$ set of $\mathrm{E}_{0}$ is broken down into three nonintersecting equivalence classes:

$\mathrm{E}_{0}=\left\{\left(\mathrm{s}_{01}\right),\left(\mathrm{s}_{02}, \mathrm{~s}_{03}, \mathrm{~s}_{06}\right),\left(\mathrm{s}_{04}, \mathrm{~s}_{05}\right)\right\}$

The following entry is used to indicate the equivalence of the items in relation to $\mathrm{R}_{0}$ :

$\mathrm{s}_{01} \equiv \mathrm{s}_{01}\left(\bmod \mathrm{R}_{0}\right)$, which is the $\mathrm{S} 1$ element is equivalent to the $\mathrm{s}_{01}$ element on the R0 module

$\mathrm{s}_{02} \equiv \mathrm{s}_{03} \equiv \mathrm{s}_{04},\left(\bmod \mathrm{R}_{0}\right)$, which is the $\mathrm{s}_{02}, \mathrm{~s}_{03}, \mathrm{~s}_{06}$ element is equivalent to the $\mathrm{s}_{01}$ element on the $\mathrm{R}_{0}$ module 
$\mathrm{s}_{04} \equiv \mathrm{s}_{05}\left(\bmod \mathrm{R}_{0}\right)$, which is the $\mathrm{s}_{04}, \mathrm{~s}_{05}$ element is equivalent to the $\mathrm{s}_{01}$ element on the $\mathrm{R}_{0}$ module

The R0 split generates a mapping many $E_{0}$ by many $E$ elements which are the equivalence classes of $s_{1 i} € E_{i}$. The map $E_{1}=f_{1}\left(E_{0}\right)$ associated with each element $s_{0 i} € E_{0}$ the class $\mathrm{s}_{1 \mathrm{i}} € \mathrm{E}_{1}$ to which it belongs.

So, in the above example, many E1 consists of three elements:

$\mathrm{E}_{1}=\left\{\mathrm{s}_{11}, \mathrm{~s}_{12}, \mathrm{~s}_{13}\right\}$,

Consider many $E_{o i}$ of all those elements $s_{0} € E_{0}$ for which, under the mapping $f_{1}$, the element $\mathrm{s}_{1 \mathrm{i}} €_{\mathrm{E} 1}$ is associated. This set is a complete inverse image of the element s1i and is denoted by $\mathrm{f}_{1}-1\left(\mathrm{~s}_{1 \mathrm{i}}\right)$, i.e.

$\mathrm{E}_{0 \mathrm{i}}=\mathrm{f}_{1}^{-1}\left(\mathrm{~s}_{1 \mathrm{i}}\right) ; \mathrm{s}_{1 \mathrm{i}} \in \mathrm{E}_{1}$.

For the case in question

$\mathrm{E}_{01}=\left\{\mathrm{s}_{01}\right\}$,

$\mathrm{E}_{02}=\left\{\mathrm{s}_{02}, \mathrm{~s}_{03}, \mathrm{~s}_{06}\right\}$,

$\mathrm{E}_{03}=\left\{\mathrm{s}_{04}, \mathrm{~s}_{05}\right\}$.

Now we define the equivalence class $\mathrm{s}_{01}$, as a relation on the sets $\mathrm{E}_{0 \mathrm{i}}, \mathrm{X}_{0 \mathrm{i}}, \mathrm{Y}_{0 \mathrm{i}}$, and $\mathrm{P}_{0 \mathrm{i}}$

$\mathrm{s}_{1 \mathrm{i}} \subset \mathrm{E}_{0 \mathrm{i}} \times \mathrm{X}_{0 \mathrm{i}} \times \mathrm{Y}_{0 \mathrm{i}} \times \mathrm{P}_{0 \mathrm{i}}(1.2)$

$\mathrm{s}_{1 \mathrm{i}} € \mathrm{E}_{1}$,

Where $\mathrm{P}_{0 \mathrm{i}}$ is a variety of possible types of relationship between elements of the $\mathrm{E}_{0 \mathrm{i}}$ set,

$\mathrm{X}_{1 \mathrm{i}}, \mathrm{Y}_{1 \mathrm{i}}$ - input and output objects of the $\mathrm{s}_{1 \mathrm{i}}$ subsystem

Relation (1.2) defines $\mathrm{s}_{1 \mathrm{i}}$ as some subsystem of the original system $\mathrm{S}$, and the variety $\mathrm{E}$ of all such subsystems can be considered as the element base of the aggregated subsystem $\mathrm{s}_{1} \subset \mathrm{S}$.

The continuation of the described split procedure for $E_{1}$ and $E_{2}$ and the subsequent elements of the bases give rise to a hierarchy of all the more aggregated subsystems of $s_{n} \subset$ $\mathrm{s}_{\mathrm{n}-1} \subset \ldots \subset \mathrm{s}_{1} \subset \mathrm{S}$ and their elemental bases.

$E_{0}, E_{1}=f_{1}\left(E_{0}\right) ; \ldots ; E_{k}=f_{k}\left(E_{k-1}\right) ; \ldots ; E_{n}=f_{n}\left(E_{n-1}\right)$.

In the general case, on every $\mathrm{k}-\mathrm{M}$ aggregation level, we have subsystems

$\mathrm{s}_{\mathrm{ki}} \subset \mathrm{E}_{\mathrm{k}-1 \mathrm{i}} \times \mathrm{X}_{\mathrm{ki}} \times \mathrm{Y}_{\mathrm{ki}} \times \mathrm{P}_{\mathrm{k}-1 \mathrm{i}}(1.3)$

$\mathrm{s}_{\mathrm{ki}} € \mathrm{E}_{\mathrm{k}}$,

Subsystems (1.3) form the elemental base of $E_{k}$, the aggregated system $s_{k}$.

Typically, design systems are complex multi-level hierarchical systems consisting of many interacting elements and subsystems [4].

In accordance with the above reasoning, each structural element of the organizational design system should be considered as an "input-output" system, or as $\mathrm{s}_{0}$ system. Each element of this system is a purposeful system $\mathrm{s}_{0}{ }^{\mathrm{T}}$.

In a production design system, which is a particular type of a more general organizational system, each element has a specific production role associated with a particular person's position in the production team. Thus, the elemental base of the design system is formed by subsystems, their elements, designers, and each designer carry out the transformation of resources in accordance with the ratio $\mathrm{s}_{0} \subset \mathrm{X}_{0} \mathrm{x}_{0}$.

The composition of the input and output resources of each structural element s0 of the system $\mathrm{S}$ varies depending on the production and social role that this element plays in this system.

The performance of the production and social role is always connected with the need to make decisions on the organization of actions: either own or other people, or whole teams.

Organizing action is a deliberate limitation of the possible diversity (freedom) of action.

Making such decisions on the organization's actions of people and collectives (divisions) is the essence of organizational management. 
A characteristic feature of the organizational system that distinguishes it from systems of another type, for example, technical, is that each of its elements makes decisions on the organization of actions, which is a crucial element.

Some of them make decisions on organizing only their actions. These are the executive elements.

The elements that make decisions about organizing not only their own actions but also the actions of some other elements that are merged or not merged into teams or organizations are the guiding elements of the system.

Since each element of the organizational system makes decisions on the organization of actions, which carries out information processing, then howling the organizational system as a whole is a system of information processing.

The most important feature of each element of the organizational system is as follows: regardless of whether he receives leading or coordinating influences from another element of this system, he himself makes the final decision on the organization of his actions and the actions of the elements subordinate to him.

This fact, among many others, is the asymmetrical cause of uncertainty in the behaviour of the elements of the organizational system and, therefore, the main source of difficulties in organizational management.

The structural element $\mathrm{s}_{0}$ can change its production and social role in accordance with the needs of the global goal of the functioning of the organizational system and the objective laws governing the transformation of the resources of this system. All structural elements of the production system operate in accordance with the global goal of this system and the laws governing the transformation of its resources. This activity is realized at any given moment by the fulfilment of one or another production and social role.

In the process of production and social activity, the structural elements of the organizational system cannot continuously change its role. A change in the role played can only occur when the structural element has played to the end, entrusted to him, albeit the simplest, but completely finished production or social role. As such an elementary production role, it is advisable to adopt the maximum autonomous sequence of elementary actions.

Such a maximum autonomous sequence is an indivisible quantum of resource transformation as a separate structural element (module) of the organizational system.

If we transform a resource, we will call any change in the quantity or quality of a resource at a given point in space.

The elementary transformation will be called such a transformation, which has a clearly expressed beginning and end, also cannot be artificially dissected into simpler transformations with a clearly expressed beginning and end. Elementary conversion of resources, performed by a person, we call elementary action.

In accordance with these definitions, any simple, clearly defined manipulation performed by a person with materials, tools, equipment, is an elementary action. Any simple logical or arithmetic operation performed by a person is also an elementary action.

As a rule, an elementary action is performed by one structural element of the organizational system. However, to perform some of these actions, several structural elements must be involved at the same time $[1,15]$.

\section{Discussion}

The self-organizing model for a design system within a certain organization (project institute) can be built, for example, using network models. Best of all, using generalized network models. It is better to apply for the following order. First, perform a ranking of units and groups according to the importance of the vertices that correspond in this case to 
the degrees of the vertices of the graph. The degree of a vertex of a graph is calculated as the number of links converging to any unit (vertex of the graph) from other groups and units of this field (from other vertices of the graph). Units are placed in the corresponding ranking table. The ranking is done by IBM.

Then, the multi-connectedness of the vertex is eliminated by maintaining a connection with the vertex in which the "semantic specific gravity" of the vertex in question is greater than in the remaining adjacent vertices associated with it. Thus, a network is constructed that displays the structure of the system.

A similar approach is implemented in the form of a graphic display of the design system.

Moreover, the structure is a special characteristic of the design system. This is because the structure is, firstly, the most general and, secondly, the structure reflects the more general, essential and at the same time stable properties of the system. By identifying the objective laws that exist in the structures, the head of the design organization is left to decide the issues related to the division of structural units to form a common structure.

The creation of new forms occurs in certain conditions, namely:

- Activities of the design organization in a CAD environment;

- $\quad$ The existing need for project organization personnel for more advanced activities;

- The readiness of the management of the design organization to change the mode and conditions of working time;

- Availability of necessary resources or willingness to create new resources.

The structure described above should have characteristics that allow building relationships between system elements and take into account changes in the conditions of the external and internal environment.

Elements of the structure are individual employees, services, and units of the management apparatus, performing certain functional duties within their authority. For the successful work of the new structures, it is necessary to know their subordinates, the correct placement of personnel, for which it is necessary to clearly understand the roles within the project organization, where the participants are elements both within the structure itself and outside it.

The activities of the structure participants in the framework of the construction project are carried out under the previous conditions, solving issues in the creation of design estimates. The interaction of all participants is ensured through specially selected information systems and programs that allow both to create optimal conditions for communication between designers, as well as analysis of activities and tasks in accordance with the established deadlines

The design results and the effectiveness of the design organization are directly dependent on how and in what format designers will be combined. At the same time, groups of employees united to carry out the project using a wide variety of electronic technologies to carry out design work and communication.

Many structural elements that perform one elementary action form an organizational module $[5,6,7,8,9,10,11,12,13,14,15]$.

Thus, the organizational module is a generalized executor of elementary actions, consisting of one and in some cases several or even many structural elements of the organizational system.

Therefore, the organizational module is the module of the organizational system.

The technological and information module can only function when the corresponding organizational module is connected to it. 


\section{Conclusions}

The organizational system interacts with resources by connecting the organizational modules of this system to technological and information modules.

The introduced concepts allow us to define organizational management as a process of redistributing modules of an organizational system by technological and information modules.

\section{References}

1. V.P. Ignatov, Intelligent technology building design modeling (2012)

2. S. Sinenko, MATEC Web of Conf., 112, 09007 (2017), DOI: 10.1051/matecconf/201711209007. IManE\&E 2017

3. S. Sinenko, A. Slavina, MATEC Web Conf., 106, (2017), DOI https://doi.org/10.1051/matecconf/201710608016 23 May 2017

4. Automation systems for design in construction: a textbook for universities (2014)

5. S.A. Sinenko, A.O. Feldman, Industrial Engineering and Modern technologies, 463, 042010, (2018) doi:10.1088/1757-899X/463/4/042010.

6. H. Dzhusoev, S. Sinenko, A. Slavin, Earth science, 272, 032238, (2019), doi:10.1088/1755-1315/272/3/032238 1

7. K. Losev, V. Chulkov, R. Kazaryan, Materials Science and Engineering, 463 032085, (2018)

8. K. Losev, V. Chulkov, R. Kazaryan, Materials Science and Engineering, 463, 032084, (2018)

9. R. Kazaryan, MATEC Web of Conferences TransSiberia, 239, (2018)

10. A. Slavina, E3S Web of Conferences Topical Problems of Architecture, Civil Engineering, and Environmental Economics, 000010733, (2018), doi.org/10.1051/e3sconf/20199108066.

11. A. Slavina, Virtual structure in the design department of a construction organization // Science and Business: Development Paths, 2(80), 32-35 (2018)

12. A. Slavina, Improving the efficiency of the design organization unit based on the virtual environment, 4(1004), 48-50 (2018)

13. A. Slavina, Creation of virtual divisions of design organizations, 2(92), 135-138 (2019)

14. A. Slavina, Remote work in the design of construction, 2(92), 138-141 (2019)

15. A.A. Lapidus, V.I. Telichenko, D.K. Tumanov and all, Development of methods of technology and organization of construction production for solving energy efficiency problems, 2, 10-16 (2014) 